\title{
Energy Crisis and Productive Inefficiency: Micro-Evidence from Textile Sector of Faisalabad
}

\author{
HAIDER ALI and MUHAMMAD NAWAZ
}

\section{INTRODUCTION}

Energy, being an essential component of every production process, plays a pivotal role in the growth process of a country. The production process has undergone a massive transition from labour intensive to energy intensive techniques [Stern and Cleveland (2004)]. Now, it is widely recognised that industrialisation is an energy-intensive process; hence, uninterrupted supply of energy is necessary to keep the production process in run. In addition, high percapita energy consumption is considered as an indicator of the level of economic development. This positive correlation between energy consumption and output growth (and development) led many countries, particularly developing ones, to design policies for subsidised energy provision with focus on supply-side in late eighties. At the same time, some European countries (i.e. Germany, Denmark, Belgium, Sweden) formulated energy policy focusing on demand-side (energy conservation), and achieved smaller growth rates in energy consumption without any reduction in economic growth [Pintz (1986)].

After recent episodes of oil price increase (started from 2006-07), tight financial position and huge trade deficits forced many developing countries (Pakistan, in particular) to pull out, at least moderately, from the policy of subsidised energy supply [Alahdad (2012) and Malik (2012)]. The energy demand in Pakistan has also been increasing steadily in every sector of the economy and future energy need of Pakistan is forecasted to be, at least, three times that of today within next two decades. ${ }^{1}$ The focus of energy policy in Pakistan has been the demand side as it is believed that energy crisis in Pakistan is a management and not a capacity issue. ${ }^{2}$ Besides, demand-side policies are being adapted to save not only capital but also foreign exchange of the country.

Haider Ali < haider@pide.org.pk> is Lecturer (Economics) at the Pakistan Institute of Development Economics, Islamabad. Muhammad Nawaz<mnawaz@pide.org.pk> is Junior Researcher at the Pakistan Institute of Development Economics, Islamabad.

Authors' Note: The authors are highly thankful to; Dr Rehana Siddiqui for her support throughout this research study, Dr Sajid Amin for helpful suggestions in preparing questionnaire and M. Sajid Rafique and M. Bilal Maqbool in conducting the survey. We are also grateful to Mian Imtiaz Ali from Almaraj Hosiery Industry for his time and effort in arranging the meetings with different industrialists and to help our enumerators during the survey. The financial assistance for this research paper is provided by the Pakistan Institute of Development Economics (PIDE), Islamabad.

${ }^{1}$ NTDC Report (2011).

${ }^{2}$ Framework of Economic Growth 2012, Planning Commission. 
These demand side energy policies e.g. energy conservation, energy-prices mechanism etc. have proved to be a serious constraint in the industrial growth of Pakistan [Siddiqui (2004); Aqeel and Butt (2011) and Malik (2012)]. Importantly annual production loss due to power shortages is about two percent of gross domestic product [Abbasi (2011)]. Various studies [i.e., Bose, et al. (2005) and Wijayatunja and Jayalath (2008)] have tried to estimate the output loss due to power outages. In case of Pakistan, a few attempts have been made to quantify the cost of unserved energy [Lahore Chamber of Commerce and Industry (1986); Pasha, et al. (1989) and Siddiqui, et al. (2011)]. Siddiqui, et al. (2011) also quantified the industrial production loss due to shift hours whereas the other studies focused on power outages only.

Textile being the largest industrial sector of Pakistan generates the country's highest export earnings of about 58 percent; providing the bulk of employment (39 percent) to largely unskilled as well as underutilised workforce, and contributes 8.5 percent to GDP. ${ }^{3}$ Textile production is comprised of cotton ginning, yarn, fabric, home textiles, towels, hosiery and knitwear, readymade garments and canvas. These components are being produced both in the large and small scale organised sector as well as in unorganised cottage/small and medium units.

Textile industry is presently comprised of 521 textile units with installed capacity of 10.0 million spindles and 114000 rotors making Pakistan to have third largest spinning capacity in Asia with spinning capacity in Pakistan being 5 percent of the total world capacity and 7.6 percent of the capacity in Asia. ${ }^{4}$ Despite this vigorous and export oriented textile industry, dismal performance of textile exports (decreased from 65 percent of total exports in 2007 to 53 percent in 2012) $)^{5}$ can be mainly attributed to the stifling power shortages. This crisis has left investors fighting for their survival and, in some cases, they are shutting down production units in Pakistan and/or moving abroad (especially in Bangladesh). In other cases, some export-specific production units are, now, unable to meet international orders and have converted into local production units with capturing local market in order to fulfil its average fixed cost. Besides, the power crisis caused prolonged delays in delivery schedule both at intra and inter industry level resulting in less competitiveness of the industry along with tough competition from regional competitors i.e., China, India, Bangladesh etc. These problems in textile industry are structural in nature and cannot be resolved through financial support of the government [Alam (2011)].

Textile production is not only energy but also time consuming process where a conversion of cotton into single type of good e.g. shirt, vest, or socks takes about two months with the involvement of many supporting sub-sectors. It is important to note that every sector of textile industry is not equally energy-intensive and has different level of energy consumption and dependency but delay in accomplishing output orders in any sub-sector involuntarily causes further delays in making the finished product. These delays cause extraordinary production losses (as both domestic and foreign customers turn back) and badly affect capability of the textile industry. Furthermore, energy gap also varies among different sectors of the industry due to disparate scale of production

\footnotetext{
${ }^{3}$ Ministry of Textile Industry Report 2013.

${ }^{4}$ Pakistan Textile Journal (Various Issues).

${ }^{5}$ Pakistan Economic Survey, 2012-13.
} 
and input mix. Large scale production sectors are using alternative sources of energy like generators; thus, reducing their energy gap and production loss at increased cost of final products. Therefore, high energy intensive industries may not have higher energy gap relative to less energy intensive industries that are unable to purchase costly energy inputs due to capital constraints or bad market conditions (as less orders reduce economies of scale).

These sector-level differences of energy gap and resulting production loss have not been analysed earlier in case of any industry in Pakistan. A recent study by Siddiqui, et al. (2011) calculated total industrial output loss by taking into account all major industries including textile and reported that output loss falls in the range of 12 percent to 37 percent due to power outages. This study does not take into account the production delays by sub-sectors of textile industry at all. This restrictive assumption of homogeneity of sub-sectors (at least, with regard to energy consumption) may result in a bias towards under-estimation of the impact of energy shortage on production cost for the reason discussed above. Further, the study is based on a survey conducted in the second quarter of 2008 while taking 2007 as the reference year. It cannot, therefore, account for impact of recent developments regarding energy crisis in the textile industry i.e., severity of power outages, capital flight, increased use of alternative energy resources etc. Against this backdrop, the present study would significantly contribute to our understanding about the impact of energy crisis on textile sector.

Based on primary data from various sectors and sub-sectors of textile industry, this study reveals which sub-sectors of textile industry are more energy deficient relative to other ones. This work also attempts to calculate the magnitude of production losses due to different size of lags in accomplishing production orders. Most importantly, it is the first attempt to estimate producers' willingness to pay for uninterrupted energy supply. Therefore, the contribution of this study is twofold in the sense that it not only estimates production loss of textile sector due to unavailability of energy but also it reports producers' willingness to pay for uninterrupted energy supply at various sub-sectors level.

The remainder of the study is organised as follows. Section 2 details the data, variables and methodology. Section 3 contains a brief discussion on the results while final section concludes the study.

\section{DATA, VARAIBLES, AND METHODOLGY}

The study primarily utilises the primary data from the textile industry of district Faisalabad, Pakistan. According to the Faisalabad Chamber of Commerce and Industry [FCCI (2013-14)], there are almost 1090 registered units of different sub-sectors of textile industry. According to Economic Survey of Pakistan (2012-13), this industry is categorised into ginning $(G I N)$, spinning $(S P N)$, weaving (WEA), fabric and knitting $(F A B)$ and cotton cloth sectors whereas cotton-cloth sector is further subdivided into sizing (SIZ); dyeing, chemical and processing (DCP); textile (TEX); hosiery (HOS); readymade garments $(R M G)$ and printing and embroidery (PEM). This study covers 125 firms (sub-sectors of textile industry) randomly selected according to their percentage share in the market as shown in Figure 1. Fiscal year 2008 is taken as the reference year because at that time energy crisis was in initial stages. 
Fig. 1. Market Share of Different Sectors of Textile Industry in Faisalabad

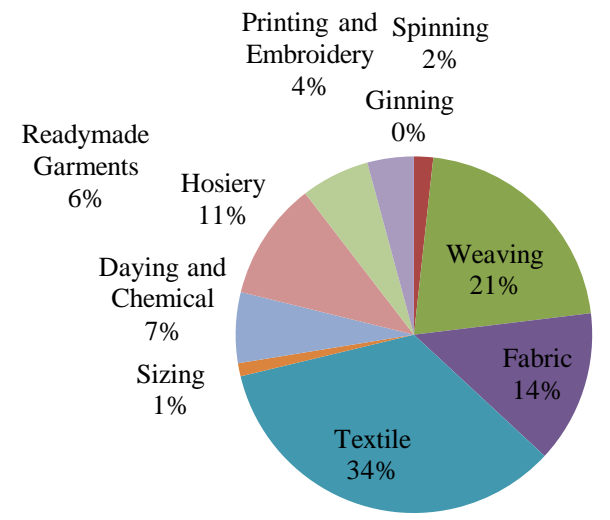

Marke Share of Textile Sub-sectors

Source: The Faisalabad Chamber of Commerce and Industry (FCCI, 2013-14).

In Pakistan, energy crisis has badly affected the production process of major local and export oriented textile sectors of Pakistan. In order to identify the production loss $(P L)$ and its magnitude due to energy crisis in every sector of the industry, Siddiqui, et al. (2011) is followed. Firstly, the production and energy loss is computed as a whole and sub-sector-wise. The production loss is product of output per labour-hour $(O P L H z)$ and total loss of labour hours $(T L L H z)$ in each sub-sector.

$$
\begin{array}{lllllll}
P L_{i}=(\mathrm{OPLHz})_{i} \times(\mathrm{TLLHz})_{i} & \ldots & \ldots & \ldots & \ldots & \ldots & \ldots
\end{array}
$$

where $i$ explains number of firms. Output per labour-hour $(O P L H z)$ depends on annual output and annual working hours whereas the later is product of shift-hours of firm, number of shifts, number of workers and annual work-days. Total loss of labour-hour $(T L L H z)$ requires the average labour hour loss, number of workers and work-days. For computation of energy loss and compensated energy-loss, energy loss per-day without alternative source $(E L W A S)$ is calculated as follows.

$$
\begin{array}{llllllll}
E L W A S & =E R H \times L S H & \ldots & \ldots & \ldots & \ldots & \ldots & \ldots
\end{array}
$$

where $E R H$ and $L S H$ are energy requirements per-hour and load-shedding hours per-day, respectively. The major contribution of this study is that it takes both electricity and gas as sources of energy inputs measured in their respective units. Energy required per-hour is obtained by dividing the energy unit consumed per-month $(E U C M)$ and working hour per-month $(W H M)$.

$$
\begin{array}{llllllll}
E R H=E U C M / W H M & \ldots & \ldots & \ldots & \ldots & \ldots & \ldots
\end{array}
$$

Working hour per-month is attained by multiplying working hour per-day and total work days of a firm. After computing the energy loss per-month, the compensated energy loss is calculated which is the difference between energy loss per-day without the use of alternative-source (ELWAS) and energy loss per-day after using the alternative source $(E L A A S)$ such as stand-by generators. 


$$
C E L M=E L W A S-E L A A S
$$

The energy loss per-month in the presence of alternative source makes Equation (2) as:

$$
E L A A S=E R H \times(L S H-U A S H) \quad \ldots \quad \ldots \quad \ldots \quad \ldots \quad \ldots \quad \ldots
$$

Here $U A S H$ is the usages of alternative source per-hour and the computation of ERH requires a change in Equation (3) in the light of Equation (5). The whole process gives the production loss, energy loss and compensated energy loss for both the whole and subsector wise. Production order delays are the delays which firms are facing due to the interruption in energy provision. Total number of order delays in particular year and number of order delay days per-order are used for the analysis.

\subsection{Producer's Willingness to Pay for Uninterrupted Energy Supply}

On-going energy crisis has reduced the production level and the producers of textile sector are compelled to use alternative energy source such as heavy stand-by generators and self-production of energy. These producers are paying large amount for uninterrupted energy to fulfil their production orders. So, this sub-section relates with the producer willingness to pay for uninterrupted energy supply (alternative energy source).

In order to analyse the producer willingness to pay for alternative energy sources (input), the work(s) of McConnell and Bockstael (2005), modified by Zapata and Carpio (2012) are followed. The theoretical stance of producer willingness to pay requires both consumer and producer side. On consumer and producer side, utility maximisation framework subject to budget constraint and both profit maximisation as well as cost minimisation framework subject to production constraint are required. After having the indirect utility function, indirect profit function and cost function from the optimisation framework, the compensated and equivalent variation need to be mentioned. Non-labour income $\bar{h}$ is assumed to be function of profit that can be obtained from the linkages between the consumer and producer. $\bar{h}=\bar{h}\left(\pi\left(p_{y}, r, q\right) k\right)$, and written as:

$$
Z\left[\bar{h}\left(\pi\left(p_{y}, r, q\right), k\right), L, P_{Z}\right]=Z_{0} \quad \ldots \quad \ldots \quad \ldots \quad \ldots \quad \ldots
$$

where, $L, P_{z}$ and $r$ are non-labour income, prices of goods used by consumer and input prices, respectively. In compensated variation $(\mathrm{CV})$ and equivalent variation (EV) concept, change in the vector of input quantity " $q$ " from " $q_{0}$ " to " $q_{1}$ " make the amount of money to hold the condition described below:

$$
\begin{aligned}
& Z\left[\bar{h}\left(\pi\left(p_{y}, r, q_{0}\right), k\right) L, P_{z}\right]=Z\left[\bar{h}\left(\pi\left(p_{y}, r, r_{1}\right), k\right)-C V, L, P_{Z}\right] \\
& Z\left[\bar{h}\left(\pi\left(p_{y}, r, q_{0}\right), k\right)+E V, L, P_{z}\right]=Z\left[\bar{h}\left(\pi\left(p_{y}, r, q_{1}\right), k\right), L, P_{Z}\right]
\end{aligned}
$$


Equations (7) and (8) represent the economic values that producer is willing to pay for better input quantity level. It is obvious that positive CV and EV measures lead to the better welfare and negative $\mathrm{CV}$ and $\mathrm{EV}$ generate the welfare loss. CV and EV can also be explained by the producer willingness to pay (WTP) function d, defined as:

$$
d=\bar{h}\left(\pi\left(p_{y}, r, q_{1}\right), k\right)-\bar{h}\left(\pi\left(p_{y}, r, q_{0}\right), k\right) \quad \ldots \quad \ldots \quad \ldots \quad \ldots
$$

$\mathrm{CV}$ and EV functions are described above which depend on the initial and final levels of non-labour income [McConnell (1990)]. The best availability of any input quantity/level, " $q_{1}$ " may increase the profit as $\mathrm{d}>0$. In addition, it also represents the maximum amount of profit that producer is willing to accept (forgo) to give up (obtain) the benefits of new input quantity level, " $q_{1}$ ".

It has been assumed that non-labour income is a linear function of firm profit and other factors defined by " $k$ ". It can also be assumed that change in input quantity " $q$ ", from " $q_{0}$ " to " $q_{1}$ " is also the linear function of the difference in profits, written as:

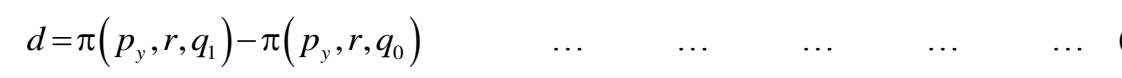

The above equation yields that the maximum amount of money a producer is willing to pay for the improvements of input quantity level which may reduce the difference between ex-post (after new input) and ex-ante (before new input) firm's profit levels.

In our analysis, the old input level is described by the current energy provision to all industrial sectors of Pakistan. Water and Power Development Authority (WAPDA) and Sui Northern Gas Pipeline Limited (SNGPL) have been the supplier of electricity and gas provision to all textile industries of Faisalabad, respectively. The ongoing energy crisis has badly affected their production level and they have to rely on alternative energy source such as heavy standby generators, working on oil, solar energy plants and other such expensive opportunities to run their industries. So, " $q_{0}$ " is energy provision in form of electricity and gas and " $q_{1}$ " are alternative expensive energy sources.

It is also apparent that alternative energy sources are more expensive as compared to traditional energy sources. That is why, industrialists pay higher amount for that which reduces their profit as well (if price remains same). So, " $r$ " is energy price that is categorised in two components " $r_{0}$ " and " $r_{l}$ ", where former is the price of traditional energy provision and latter is the price of alternative energy sources.

The analysis requires the specific form of production function for both cost minimisation and profit maximisation. From these forms, we can drive all the equations written above and extend the analysis for comparative statics of WTP variation function. It is also helpful for the sign and implication of input price effect, output price effect and input quality effect. The expected sign are as:

$$
\begin{array}{lllllllll}
\frac{\partial d}{\partial r_{0}}<0, & \frac{\partial d}{\partial r_{1}}<0 & \ldots & \ldots & \ldots & \ldots & \ldots & \ldots
\end{array}
$$


For better input quantity level or alternative energy source, the willingness to pay for producer would be higher and the variation function for own and cross price is negative. ${ }^{6}$

\section{RESULTS AND DISCUSSION}

This section presents the results of production loss and number and duration of production order delays due to energy crisis in different sub-sectors of textile industry. In addition, willingness to pay (WTP) responses for uninterrupted energy supply across the sub-sectors will be discussed.

\subsection{Production Analysis}

Energy crisis forced all sectors of the industry to produce less than their potential levels. However, due to different scale of production and level of dependency on energy inputs, the gap between actual and potential production level varies across the sectors. Figure 2 depicts theses production capacity gaps.

Fig. 2. Current Production Capacity of Different Textile Sectors

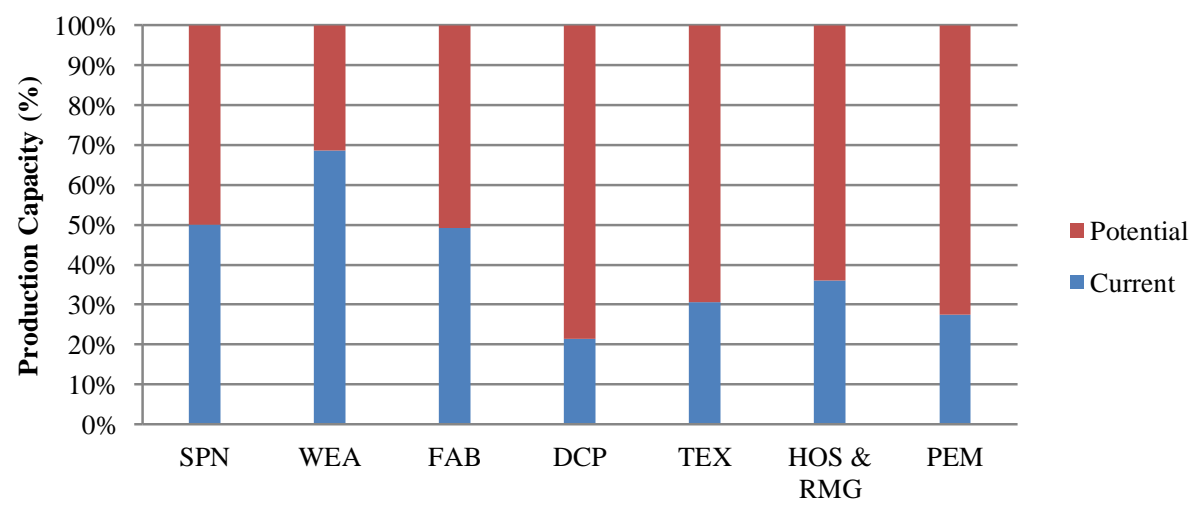

Spinning, weaving and fabric sectors have the highest use of alternative resources (mainly electric generators) and are producing 50 percent, 68 percent and 50 percent of their potential level, respectively. The maximum gap of potential and current output is apparent for textile, dyeing, chemical and processing and printing and embroidery firms. Lower production capacity in dyeing, chemical and processing $(D C P)$ sector is exerting negative effects on production in textile (TEX), hosiery and readymade garments (HOS and $R M G$ ) and printing and embroidery (PEM) as the latter sectors depend upon $D C P$. These sectors are using gas-intensive alternative resources; hence, it can be deduced that production loss is worse in gas dependant industries than in electricity dependant. Loadshedding of gas has aggravated the cost of these firms where many units have purchased boilers to keep their production process in run. Rice-waste, corn-waste and coal are being used as an input in these boilers whereas using coal as an input is subject to both quantity and quality constraints. Pakistani coal is not of good quality and there are trade restrictions on import of coal from the neighbouring countries particularly India.

${ }^{6}$ Depend on substitutions and complements input alternatives. Here, only complement is more relevant. 
Spinning and weaving and sizing have no production loss from gas shortage but the later one depends more on electricity as compared to former ones. The unserved energy-loss is higher in electricity-intensive industries than gas-intensive industries. Overall, textile, dyeing and hosiery and readymade garments firms are more energy dependant as compared to others and facing severe production crises in their industries. The current situation has also adversely affected the labour market where textile, hosiery and readymade garments and dyeing sectors are the major affectees. The situation is less severe in those sectors where a working shift consists of ten hours rather than eight hours.

It can be seen from Table 1 that labour-hour loss is the highest in the textile sector followed by hosiery and garments sectors that depend upon the former. In weaving sector, there is less labour-hour loss because large scale of production and high demand of good have allowed producers to use alternative resources at the time of electricity load-shedding. Printing and embroidery sector is also using alternative sources to continue working at time of load-shedding. Production loss is highest in textile sector followed by dyeing, chemical and processing sector under both shifting hours. Zero production loss under gas as an input in weaving and spinning sectors is because these sectors primarily depend upon electricity and use electricity generators in load shedding hours. It is important to note that production loss reduces as working hours of a shift increase from eight to ten. It basically indicates that increased labourhours are not proportionate to energy loss and firms may increase their output level by increasing their working hours.

Table 1

Production and Labour-Hour Losses (Thousands Units Per-Day)

\begin{tabular}{|c|c|c|c|c|c|c|c|c|c|}
\hline & & & \multicolumn{7}{|c|}{ Sectors of Textile Industry } \\
\hline & & & $\overline{S P N}$ & WEA & $F A B$ & $D C P$ & TEX & $H O S \& R M G$ & PEM \\
\hline \multirow{4}{*}{$\begin{array}{c}\text { Labour-Hour } \\
\text { Loss }\end{array}$} & 8-Hour Shift & Electricity & 0.12 & 0.06 & 0.11 & 0.24 & 0.99 & 0.93 & 0.06 \\
\hline & & Gas & 0.06 & 0.00 & 0.01 & 0.15 & 0.58 & 0.56 & 0.03 \\
\hline & 10-Hour Shift & Electricity & 0.12 & 0.06 & 0.11 & 0.24 & 0.99 & 0.93 & 0.06 \\
\hline & & Gas & 0.06 & 0.00 & 0.01 & 0.15 & 0.58 & 0.56 & 0.03 \\
\hline \multirow{4}{*}{$\begin{array}{l}\text { Production } \\
\text { Loss }\end{array}$} & 8-Hour Shift & Electricity & 0.01 & 1.19 & 2.81 & 13.89 & 28.58 & 2.33 & 2.74 \\
\hline & & Gas & 0.00 & 0.00 & 0.26 & 8.77 & 14.73 & 0.49 & 1.57 \\
\hline & 10-Hour Shift & Electricity & 0.01 & 0.96 & 2.25 & 11.11 & 22.95 & 1.87 & 2.19 \\
\hline & & Gas & 0.00 & 0.00 & 0.21 & 7.02 & 11.83 & 0.39 & 1.25 \\
\hline
\end{tabular}

The production loss for both 8-hour and 10-hour shifts in textile industry is shown below in Figure 3. It ranges between of 23 to 65 percent for 8 hour shift while 21 to 60 percent for 10-hour shift. This production loss is greater than the loss ( 25.6 percent) calculated by Lahore Chamber of Commerce and Industry (LCCI) for Punjab during 1984-85 crises and, also, above the range of 12 to 37 percent estimated by Siddiqui, et al. (2011) in 2008 when the energy crisis was in initial stages. 
Fig. 3. Production Loss of Textile Sector

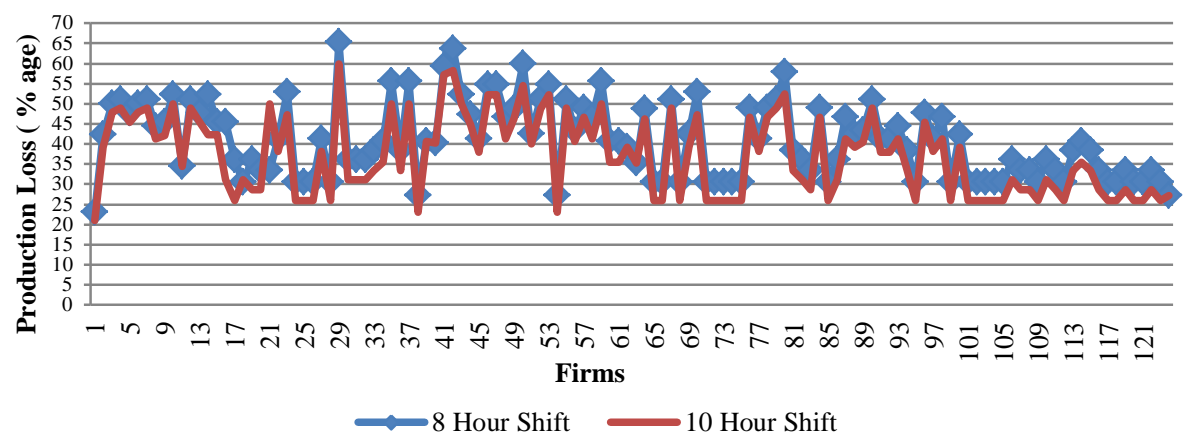

The 65 percent production loss of textile industry clearly indicates that up to 10hour per day electricity load-shedding and 4 days a week gas load-shedding has thrown textile sector into troubles resulting in huge output losses, loss of competitiveness in international market (next section will demonstrate this phenomenon) and capital outflow of major textile industries to neighbouring countries.

\subsubsection{Production Orders and Delays}

Energy crisis had adversely affected production orders, both local and foreign, by increasing cost of production and by causing delay in completion of production orders. As explained earlier, these delays in completion of orders depend on the size of the firm and production delays in other sectors of the industry on which a sector depends for intermediate product. Table 2 presents a brief picture of this scenario in the textile industry of Faisalabad.

In 2008, textile firms have the highest local and export orders as percentage of the total orders per-year while spinning sector has the least local orders in 2008 which is just 4.3 percent of total orders obtained by the whole textile sector. In 2013, international orders in all sectors have decreased as compared to reference period; expect fabric which showed growth in export orders from 6.8 to 17 percent. It is obvious that textile and hosiery and garments sectors have been unable to fulfil the international requirements and faced reduction in their export demands as compared to 2008. Further, embroidery and weaving and sizing firms have no export orders in both 2008 and 2013. The emerging results show that energy crisis has reduced the production orders in both international and national market which resulted in loss of production.

Table 2

Production Orders and Delays (Percentage of Concerned Orders Per-Year)

\begin{tabular}{lcccccccc}
\hline & \multicolumn{7}{c}{ Sectors of Textile Industry } \\
\cline { 2 - 9 } & Years & $S P N$ & WEA & FAB & DCP & TEX & HOS \& RMG & PEM \\
\hline \multirow{2}{*}{ Local Orders } & 2008 & 4.3 & 15.2 & 5.0 & 18.6 & 34.5 & 14.7 & 7.8 \\
Local Order Delays & 2013 & 3.1 & 0.2 & 3.5 & 16.5 & 39.2 & 13.3 & 7.1 \\
& 2008 & 22.8 & 47.8 & 23.3 & 31.8 & 31.7 & 16.3 & 27.3 \\
Export Orders & 2013 & 26.5 & 50.7 & 34.8 & 42.1 & 53.8 & 30.1 & 27.3 \\
Export Order Delays & 2008 & 6.4 & 0.0 & 6.8 & 3.2 & 60.3 & 23.2 & 0.0 \\
& 2013 & 3.7 & 0.0 & 17.3 & 1.9 & 45.5 & 32.6 & 0.0 \\
& 2008 & 0.0 & 0.0 & 6.4 & 0.0 & 8.2 & 11.1 & 0.0 \\
& 2013 & 0.0 & 0.0 & 9.5 & 3.6 & 10.3 & 12.8 & 0.0 \\
\hline
\end{tabular}


It can be seen from Table 2 that energy crisis has slowed down the production process in the textile industry where both local and foreign production orders have reduced in almost all sectors of the industry. Textile sector is an exception where local orders have increased in 2013 as compared to 2008. This result can be explained by looking at the export orders of this sector which has experienced a sharp decline in export orders. Unable to meet the international orders on time, the textile sector has changed its preferences from foreign market to local market so that it may fulfil its fixed cost and keep its existence in the market. It can be termed as a positive externality of recent energy crisis where local market is now enjoying more variety of textile products after energy crisis than it has before this crisis.

Increase in export orders of fabric $(F A B)$ and hosiery and readymade garments $(R A M)$ sectors are due to conversion of production plants on alternative resources and increased demand in international market of these Pakistani products. Increase in production order-delays shows that the problem of interrupted energy supply has not been addressed in correspondence with the magnitude of the crisis and the situation is getting worse.

For even a deeper analysis how energy crisis is worsening the production process, delay-days per production (local) order are presented in Figure 4. It can be seen that order delay has increased in all sectors of the textile industry except printing and embroidery $(P E M)$. Dyeing, chemical and processing sector is experiencing the highest delay duration in completion of an order due to the energy crisis.

Fig. 4. Delay-Days per Local Production Order

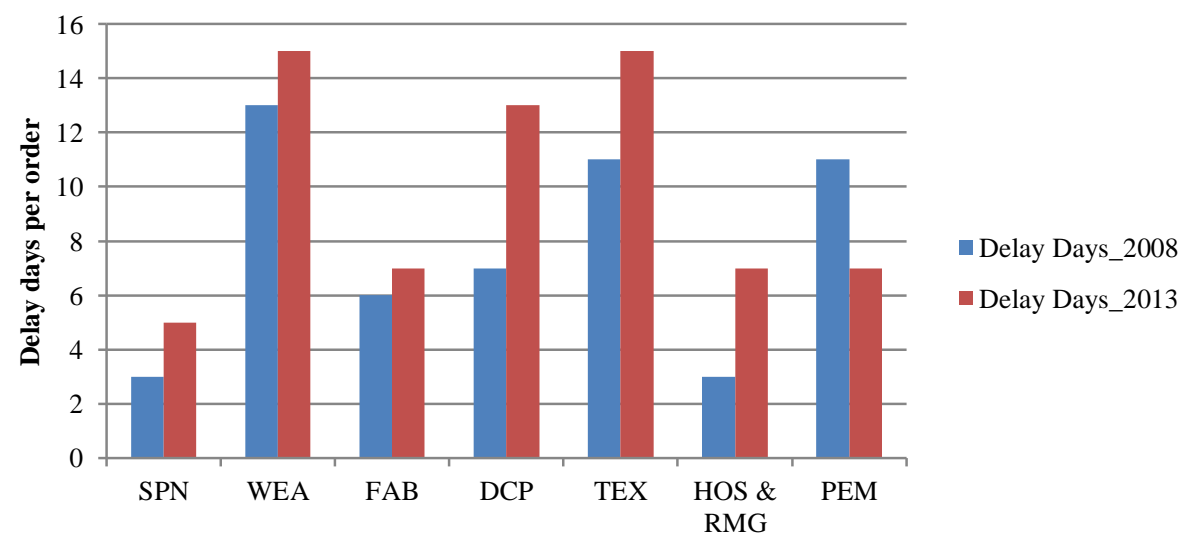

Overall the average duration of a local production order delay in the textile sector has increased from seven days to ten days that clearly shows the worsening of the crisis and hence textile production. On the other hand, export order delay cannot exceed more than three working days as a norm of international business in majority of cases.

\subsection{Energy Analysis}

Industrial sector in general and textile sector in particular is experiencing the worst energy crisis of Pakistan's history where eight hours per day scheduled electricity load 
shedding with a minimum of two hours per day unscheduled load shedding is prevalent. In addition, textile sector is facing four days a week gas load shedding that is resulting in huge production losses across the industry. Adaptation of alternative resources by firm owners have lessened the magnitude of the problem over the time but the tight financial position and growing energy crisis are making it difficult to get rid of this problem completely. Increased hours of a working shift are normally practiced to minimise the unserved energy loss but the issue becomes even more critical when the load shedding hours are pegged with peak-time working hours of the firms. Many of the firms have dual input requirement of both electricity and gas as these sectors have implanted technology where they can use whatever input is available at the time. In is notable that in presence of gas, electricity is not used for running of production process as electricity unit is costly than a unit of gas. This study analyses energy loss (both electricity and gas) faced by each sector of the textile industry, first, with respect to shifting hours of a firm and then peaktime load shedding hours.

\section{(a) Shifting Hour Criteria}

Figures 5 and 6 explain the total energy (electricity and gas, respectively) requirement of different sectors of the industry; supply of energy; how much these sectors have compensated for deficiency in energy requirement and the existing deficiency level. Electricity consumption is the highest in spinning and textile sectors that require 18.35 and 14.29 thousand units per-day, respectively. Gas consumption is highest in textile and dyeing and chemical sectors where the need is of 88.63 and 21.25 thousand units per-day, respectively. On the other hand, embroidery sector has the lowest electricity consumption per-day and fabric sector has the lowest gas consumption per-day.

Fig. 5. Electricity Loss of Textile Sectors (Per-month)

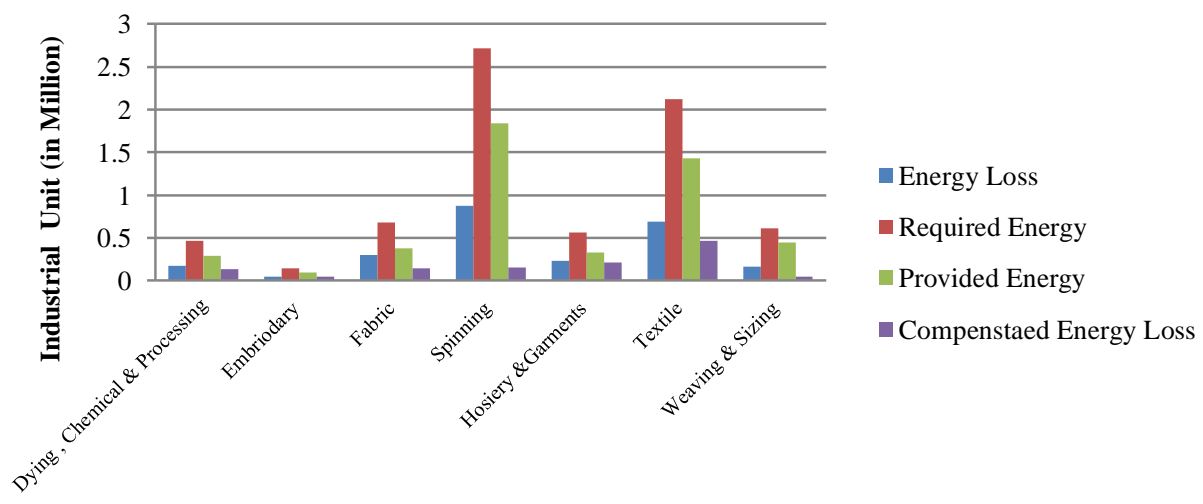

Spinning, Textile and Fabric sectors are facing severe electricity loss but the textile sector is the one that is bearing highest cost by employing alternative sources to compensate for energy loss. Although energy loss is the highest in spinning sector yet this sector is not using alternative sources to minimise its loss. Being highly electricity dependant sector, spinning needs a huge fixed cost to finance a complete alternate for smooth functioning of production process. Hosiery and garments and embroidery sectors 
are almost fully compensating their energy loss by using alternative sources. Electricity gap is minimum in $D C P$ and $W E A$ sectors where only severity of crisis (increased load shedding hours) has raised their electricity loss against their employed alternatives. Besides, $D C P$ sector is more gas dependant than electricity dependant; hence, requires less expenditure on electricity resources.

Figure 6 shows the gas requirements and shortfalls in different sectors of textile industry. Contrary to electricity, gas load-shedding is not on daily basis rather it happens according to a certain schedule of four days a week. Textile is facing the highest energy (gas) loss followed by $D C P$ and hosiery and garments. Textile sector requires 91.55 thousand units gas per-day, the highest demand in the industry and fabric has the minimum gas requirement. As a result, the textile industry is more energy intensive sector in terms of both electricity and gas.

Fig. 6. Gas Loss of Textile Sectors (Per Month)

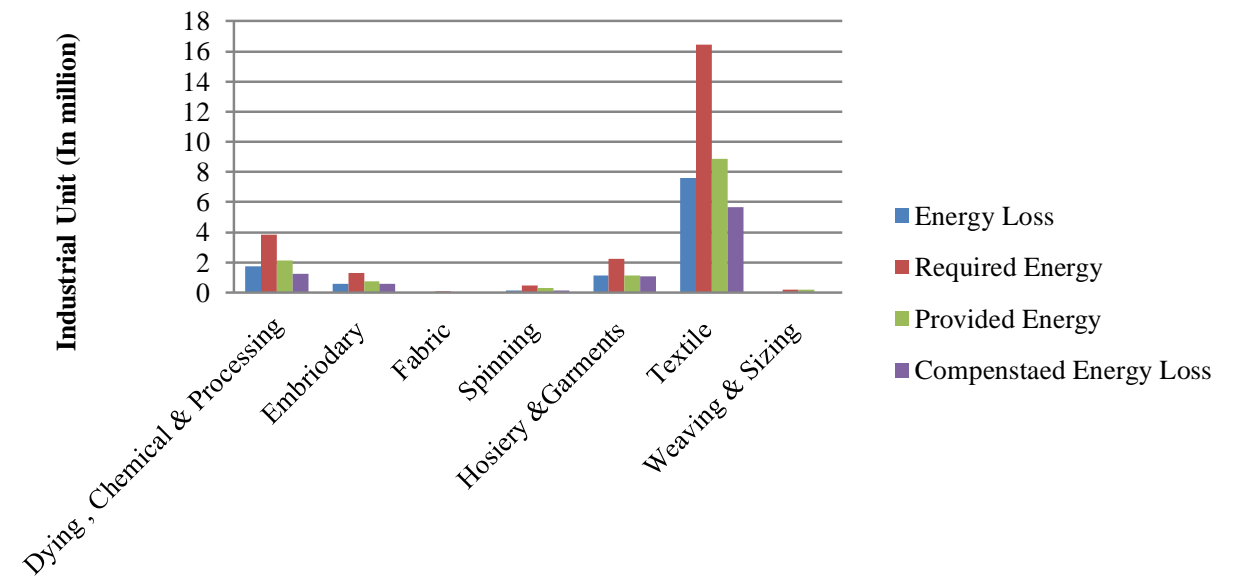

Many firms in textile sector are using boilers as an alternative resource for gas load shedding whereas wood, rice waste, corn waste and, in some cases, coal has been used as input. Environmental perspective of using these boilers is far worse but covering that cost is beyond the scope of this paper. Hosiery and garments sectors are sufficiently equipped with alternative resources to keep the production process in run in case of no energy provision.

\section{(b) Peak Time Load-Shedding Hour Criteria}

Most of the firms confirm that they face severe shortage of electricity during their peak time of business and production activity. Each value of concerned group of firms has more electricity requirements during peak times as compared to shift-hour defined above. Figures 7 and 8 explain the total energy (electricity and gas, respectively) requirement and loss situation of different sectors of the industry.

Electricity requirement for spinning sector is almost 3.2 million units per-month while government is providing only 1.8 million units. In this way, this sector is facing electricity shortage of 1.4 million units per-month and compensating 0.25 million units to 
its energy loss through standby generators and other alternative sources, left over with huge energy deficiency. The weaving and sizing firms are least compensating their energy loss same is true for shifting hour criteria.

Fig. 7. Electricity Loss of Textile Sectors (Per Month)

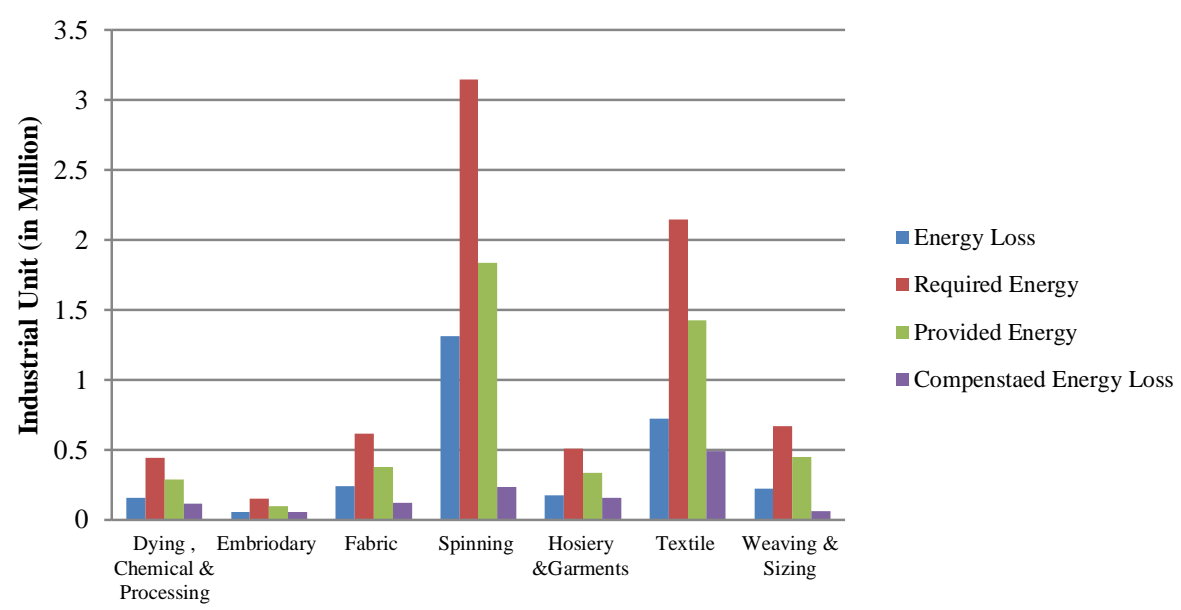

Figure 8 depicts the picture of gas using firms that have higher gas values as compared to shift-hour and weight according to shift-hour criteria. Fabric, spinning and weaving and sizing are free from the issue of gas shortage. They have less demand as well they compensate according to their requirements. But textile, dyeing, chemical and processing and hosiery and readymade garments are facing the severe shortage of gas in spite of the utilisation of alternative source in order to fulfil their requirements. In peak hour load shedding environment, we found that firms are facing the severe loss of energy and producing the less output. Overall, spinning sector is facing the high deficiency of electricity while textile and dyeing, chemical and processing are facing the huge deficiency of gas and their alternative sources cannot fulfil their requirements.

Fig. 8. Gas Loss of Textile Sub-sectors (Per Month)

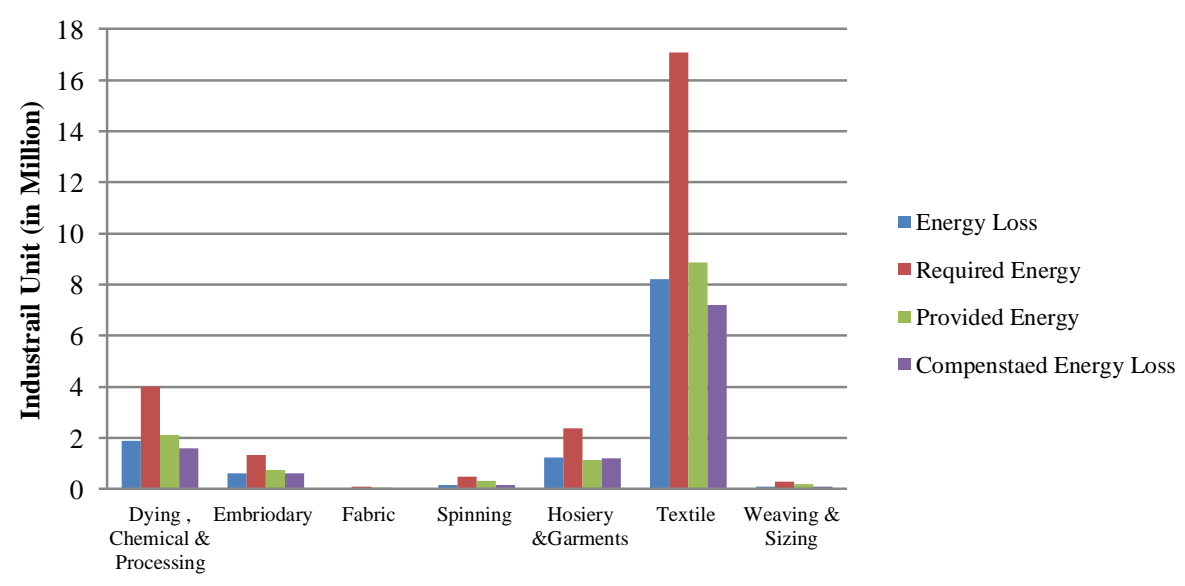




\subsection{Willingness to Pay (WTP) for Uninterrupted Energy Supply}

The shortage of energy in textile sectors has compelled producers to show their willingness to pay for uninterrupted energy supply per unit of energy. Table 3.3 presents the estimates of WTP for uninterrupted energy supply.

Table 3.3

Willingness To Pay (WTP) for Uninterrupted Energy Supply

\begin{tabular}{|c|c|c|c|c|c|c|c|c|}
\hline & \multicolumn{7}{|c|}{ Sectors of Textile Industry } \\
\hline & & $\overline{S P N}$ & WEA & $F A B$ & $D C P$ & $T E X$ & $H O S \& R M G$ & PEM \\
\hline \multirow[t]{4}{*}{ (WTP) } & $\%$ of Firms & 66.67 & 60.87 & 73.33 & 66.67 & 61.54 & 57.14 & 77.78 \\
\hline & Maximum (Rs.) & 8 & 11 & 9 & 20 & 13 & 10 & 10 \\
\hline & Minimum (Rs.) & 3 & 4 & 5 & 4 & 2 & 6 & 4 \\
\hline & Average (Rs.) & 5.50 & 6.79 & 6.82 & 9.22 & 6.25 & 8.71 & 7.29 \\
\hline
\end{tabular}

Out of 125 sample of industrial firms, only 80 (64 percent of total) were willing to pay for uninterrupted energy supply. The remaining firms were skeptical about provision of uninterrupted supply even at a higher cost of input. Less interest of firm owners in uninterrupted energy supply is due to lack of trust on public policies and/or their less ability to face further shocks after recently faced shock of higher price of electricity. ${ }^{7}$ On average more than fifty five percent firms in each sector are willing to pay higher if they are provided nonstop energy supply.

The maximum willingness to pay was $20 \mathrm{Rs}$ in $D C P$. The minimum willingness to pay is $2 \mathrm{Rs}$ in the textile firms. Textile sector has lost its foreign competitiveness due to recent energy crisis and further increase in input prices would result in complete loss of the foreign market. It has already been shown that hosiery and readymade garments have employed alternative resources for compensating their energy loss; hence, that sector is less willing to pay for uninterrupted energy supply. Interestingly, in HOS and RAM sector, those firms that are willing to pay higher for energy supply are offering high (above than average) prices per unit of energy.

In spite of all this energy and production crisis in textile industry, the average range of willingness to pay is high that shows animal spirit of the entrepreneurs of textile sectors who can make progress and bring this industry on top of the world if they were given necessary raw material, in this case energy, to keep production process in run. Sector wise willingness to pay is given below in Figure 9 where all of the curves have negative relation with the number of firms under each sector, clearly defining the shape like demand curve.

\footnotetext{
${ }^{7}$ We conducted our survey in the end of September and October at that time; the entire industry faced almost 50 percent increase in energy units. This huge increment also discourages their willingness to pay for uninterrupted energy supply.
} 
Fig. 9. Willingness to Pay for Uninterrupted Energy Supply by Textile Sectors
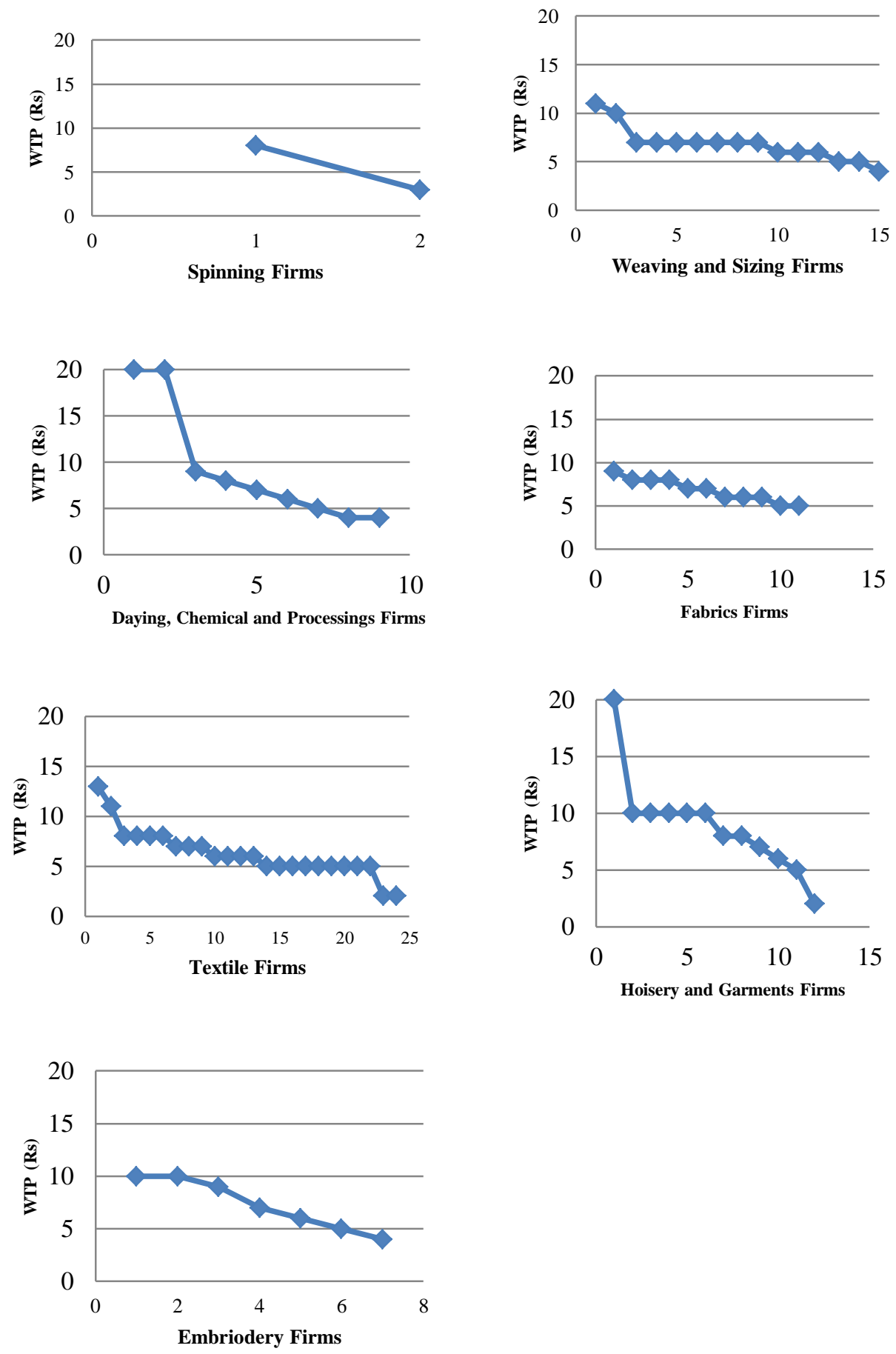
Figure 10 below is showing the willingness to pay curve of textile industry that varies from two to twenty rupees per unit for uninterrupted supply of energy.

\section{Fig. 10. Willingness to Pay Curve of Textile Industry for Uninterrupted Energy Supply}

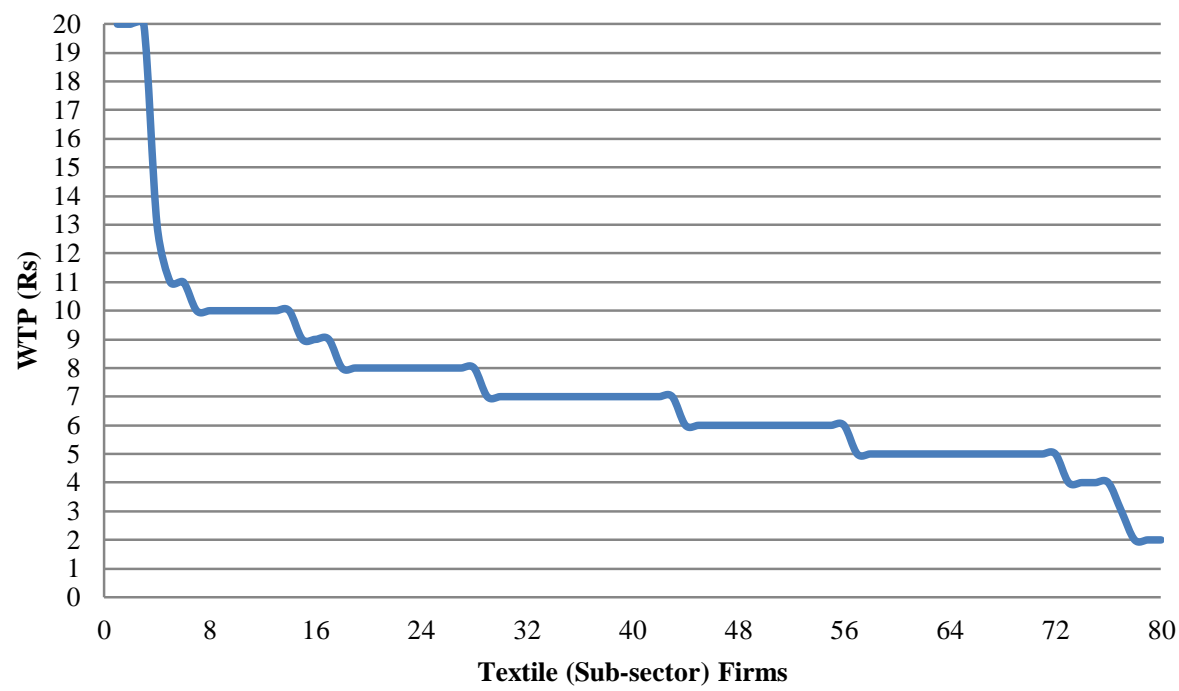

If the first and last ten firms are ignored for time being, the curve shows that most of the firms fall between the ranges of five to nine rupees per unit of energy. This curve is representing the overall willingness to pay of various sectors with different capacity of production and; hence, an approximate picture of the textile industry. This positive price signals need for new supplies of energy resources into the system.

\section{CONCLUSIONS}

Since 2007, major export oriented textile sector has been unable to meet the demand of both national and international orders due to heavy planned and unplanned energy outages in Pakistan. This outage has appeared in number of findings; intense production loss, big industrial units have been converted into smaller one, most of the industries have shut-down and large amount of capital flight (industries), in particular to competing neighbouring countries, heavy loss of competitiveness in international market and loss of business confidence by investors.

This study covers 125 firms of textile industry of Faisalabad. The results reveal that textile industry is facing 23 to 65 percent production loss for 8-hour shift and 21 to 60 percent for 10-hour shift due to interruption in energy supply. Hosiery and readymade garments sector has highest shares in production loss while weaving and sizing firms have minimum shares in production loss. Textile firms have the highest labour hour loss per-day in both shift-hours, including in hosiery and readymade garments and dyeing, chemical and processing industries. The energy outage has not only had adverse impact on production but also created major delays in production orders. The highest percentage 
increase in local order delays (as compared to its reference period, 2008) are seen in textile firms, hosiery and readymade garments and dyeing, chemical and processing industries. In international market, the percentage increase in order delays is observed for fabric firms, higher than that of textile and hosiery and readymade garments. Furthermore, dyeing, chemical and processing firms have highest order delays problem in both local and international markets. It is evident that delays in production orders clearly indicate fewer orders in near future. Most of the firms in the industry have lost their both local and international orders. Weaving and sizing firms have severe reduction in their local orders while textile firms have strengthened as compared to reference period, 2008.

The findings reveal that spinning firms are more electricity consuming and electricity deficient in Pakistan while textile firms are facing big loss in their production due to the gas outage. The entire firms in textile industry have taken the stand-by generator as alternative source in order to kill the heavy schedule and unscheduled load-shedding and to reduce the major output loss. They are trying to compensate (maximum) their energy loss according to their requirements but still they are facing the huge energy as well as production loss. This heavy energy loss has compelled them to express their willingness to pay for uninterrupted energy supply. From the sample, only 64 percent of the firms are willing to pay for uninterrupted energy supply. On average, the whole sub-sectors are willingness to pay around 5 rupees per-energy unit. The embroidery firms have highest willingness to pay while hosiery and readymade garments have least willingness to pay. These findings are helpful for the policy makers to make the best energy policy in favour of textile sector that may reduce the production loss and generate the huge employment in this sector.

\section{REFERENCES}

Abbasi, Z. (2011) Energy Crisis Costs 2 Percent of GDP Annually. Business Recorder, July 07.

Alahdad, Z. (2012) Pakistan's Energy Sector: From Crisis to Crisis- Breaking the Chain. Pakistan Institute of Development Economics, Islamabad. (PIDE Monograph Series).

Alam, Imran (2011) Impact of Financial Crisis on Textile Industry of Pakistan: Evidence from Faisalabad. (SANEI Working Paper Series, No. 11 - 02).

Aqeel, A. and M. S. Butt (2011) The Relationship between Energy Consumption and Economic Growth in Pakistan. Asia Pacific Development Journal 8, 101-110.

Bose, , R. K., M. Shukla, L. Srivastava, and G. Yaron (2005) Cost of Unserved Power in Karnataka, India. Energy Policy 34, 1434-47.

Lahore Chamber of Commerce and Industry (1986) Productivity Losses Due to Loadshedding. Lahore. (LCCI Special Report).

Malik, Afia (2012) Power Crisis in Pakistan: A Crisis in Governance? Pakistan Institute of Development Economics, Islamabad. (PIDE Monograph Series).

McConnell, K. E. (1990) Models for Referendum Data: The Structure of Discrete Choice Models for Contingent Valuation. Journal of Environmental Economics and Management 18, 19-34.

McConnell, K. E. and N. B. Bockstael (2005) Valuing the Environment as a Factor of Production. In K. G. Mäler and J. R. Vincent (eds.) Handbook on Environmental Economics, Vol. 2. North-Holland, Amsterdam. 
NTDC Report (2001) Electricity Demand Forecast based on Multiple Regression Analysis, Period 2011 to 2035.

Pakistan Textile Journal (Various Issues) URL: http://www.ptj.com.pk/2008/JournalArchive.htm

Pakistan, Government of (Various Issues) Pakistan Economic Survey. Islamabad: Ministry of Finance, Pakistan.

Pintz, Peter (1986) Demand-side Energy Policy as an Alternative Energy Strategy for Pakistan. The Pakistan Development Review 25:4, 631-644.

Siddiqui, R. (2004) Energy and Economic Growth in Pakistan. The Pakistan Development Review 43:2, 175-200.

Siddiqui, R., H. H. Jalil, M. Nasir, W. S. Malik, and M. Khalid (2011) The Cost of Unserved Energy: Evidence from Selected Industrial Cities of Pakistan. Pakistan Institute of Development Economics, Islamabad. (PIDE Working Papers 75).

Stern, D. I. and J. C. Cleveland (2004) Energy and Economic Growth. Rensselaer Working Papers in Economics, ss. 1-42.

The Faisalabad Chamber of Commerce and Industry (2013-14) www.fcci.org.pk

Wijayatunga, P. D. C. and M. S. Jayalath (2008) Economic Impact of Electricity Supply Interruptions on the Industrial Sector of Bangladesh. Energy for Sustainable Development 7:3, 5-12.

Zapata, S. D. and C. E. Carpio (2012) The Theoretical Structure of Producer Willingness to Pay Estimates. Presented at the Agricultural and Applied Economics Association's 2012 (AAEA) Annual Meeting, Seattle, Washington, D.C. 


\section{Comments}

This study is also part of the research projects being funded by the Pakistan Institute of Development Economics to promote innovative research ideas and novelty in techniques needed to explore burning issue of energy crises in Pakistan. First of all, I would like to congratulate authors for presenting well researched study on the effect of energy crises at the firm level of the worst affected industrial area of Punjab. Authors have made good contribution in the existing literature by exploring well into problems of the textile sector at the micro level in Pakistan while earlier study by Siddiqui, et al. $(2011)^{8}$ have computed total losses for industrial sector from prevailing energy crises. Authors have dealt with methodology very well by decomposing losses into output, labor hours and order delays from energy crises-defined in terms of electricity and gas load shedding at the firm level. Furthermore, the study measures the producer's maximum willingness to pay (WTP) to avoid losses from energy crises by using Hicksian approach - Compensation variation and relate it with willing to pay (WTP). The study found that about 79 percent firms of Faisalabad are willing to pay from Rs1 to Rs 20 per unit for uninterrupted supply of energy. However, I would like to make few suggestions to authors for further improvement in the study.

First, this article uses Hicksian concept of WTP in explicitly dynamic structure while Hicksian is static in nature. Theory suggests that in dynamic setting compensation variation or equivalent variation can have expected value but their relationship to the concept of willing to pay (WTP) becomes more complicated. It is because in addition to compensation variation or equivalent variation, the willing to pay (WTP) depends on the timing of the function of these values as even if compensation variation or equivalent variation are unchanging with the acquisition of new information, willing to pay (WTP) will generally not be and at any point in time willing to pay (WTP) will not be equivalent to expected $\mathrm{CV}$ or EV - this could have been incorporated as limitation of this study.

Second, authors have computed industrial losses for gas and electricity separately at the firm level which is good to look into the separate impact of the energy sources used. However, total losses from electricity and gas may also be computed and included in the tables representing losses to output, employment and order delays from electricity and gas load shedding.

Third, authors may incorporate the route map in policy guidelines for handling with energy crises in the short and medium terms especially for micro level firms. It will not only bring to light the usefulness of this kind of study hardly undertaken at micro level in Pakistan due to endless efforts and patience involved but will also help in policy targeting.

PhD Scholar,

Lubna Naz

PIDE, Islamabad.

${ }^{8}$ Siddiqui, R., H. H. Jalil, M. Nasir, W. S. Malik, M. Khalid (2011) The Cost of Unserved Energy: Evidence from Selected Industrial Cities of Pakistan. (PIDE Working Papers 75). 